\title{
Fifty years Laboratory of Horticulture
}

When the State School of Agriculture, Horticulture and Forestry at Wageningen was given university status in 1918, the Department of Horticulture was small, badly housed and offered no opportunities for research. However in 1919, 6 hectares of meadow were acquired and in the same year the architect C. J. Blaauw prepared first designs for a laboratory building to be erected on the site. The building was officially opened on 22 June 1923, after which true scientific instruction of the students could begin.

At the opening, the nine students must have felt somewhat lost among the 120 guests. The scientific staff at that time consisted of Prof. A. M. Sprenger and Mr (later Dr) H. A. A. van der Lek, the technical and administrative staff included 12 persons.

Passing rapidly across the years, we see few changes for a long time. In the initial years, there was no need to expand; after 1929, there were no funds. One of Sprenger's outstanding achievements, the initiation of a research programme on storage and processing of horticultural produce, led to the foundation of a separate institute in 1936.

During the War, the laboratory was damaged in May 1940 and reduced to an empty shell in the miserable winter of 1944/1945. When Sprenger retired in 1947, his Laboratory was on the road to recovery, but few of his goals had been reached.

With more favourable economic conditions, the Department expanded rapidly under

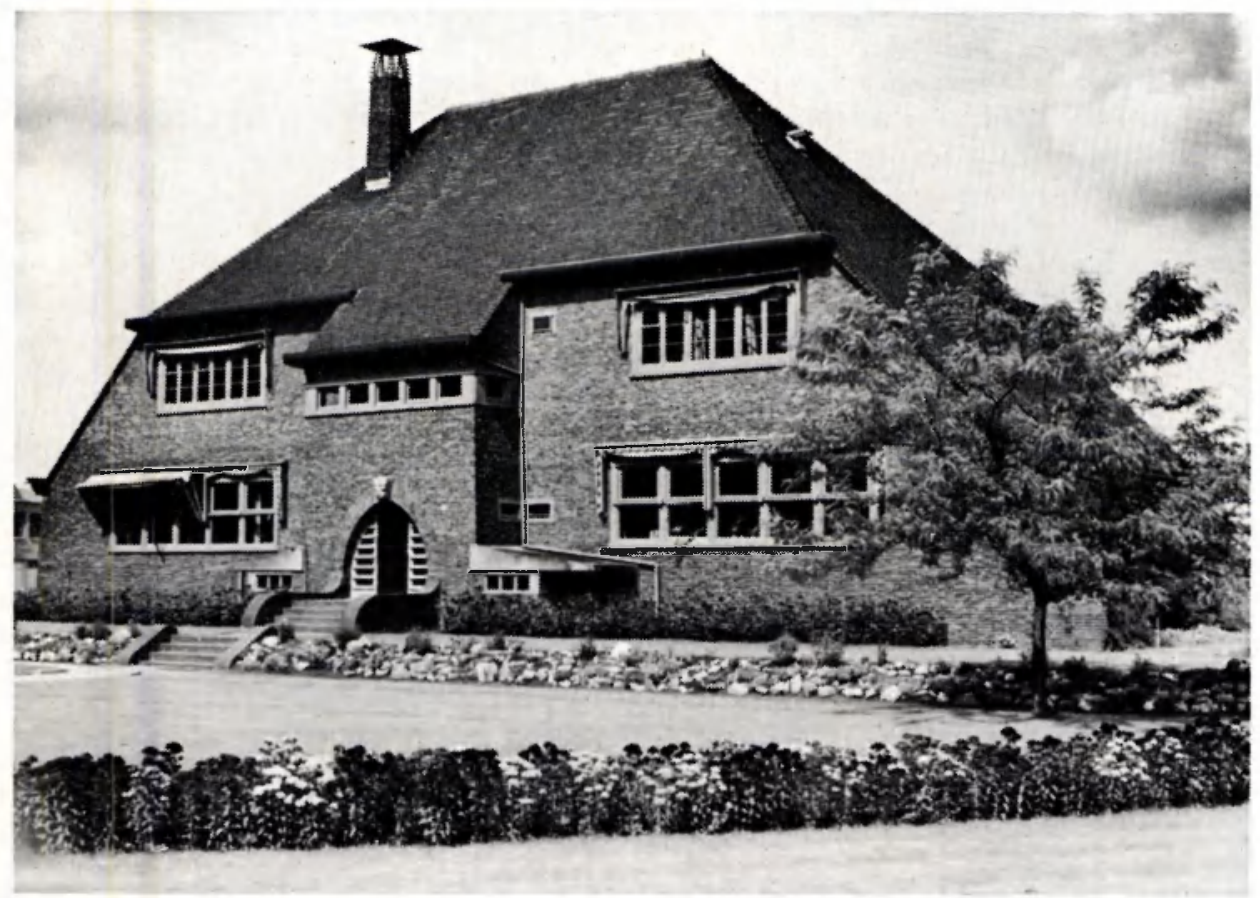

Fig. 1. The Laboratory of Horticulture from 1922-1965. 


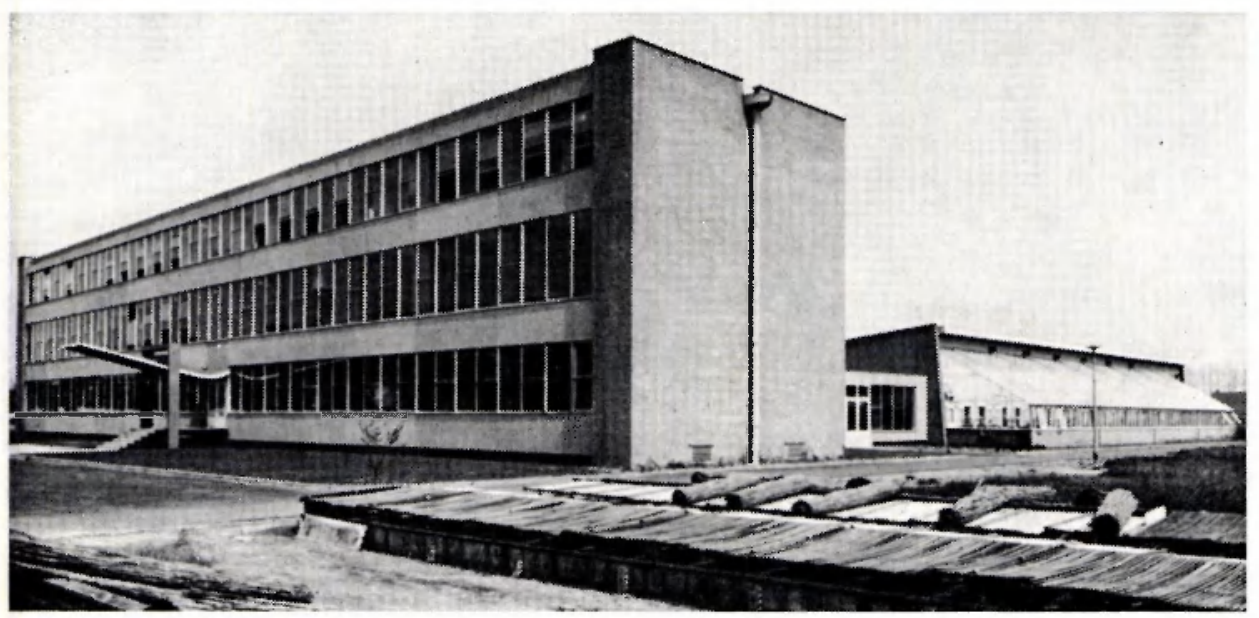

Fig. 2. The present Laboratory of Horticulture. The building to the right is a phytotron.

Sprenger's successor, Prof. Dr S. J. Wellensiek. The scientific staff gradually expanded to nine persons, and the technical and administrative staff grew accordingly. There are now about 80 students specializing in horticulture and about 35 students who take it as a subsidiary subject.

The laboratory building of 1923, charming from the outside but rather inefficient within, became too small. In 1965 the Department moved to a new building: large, austere and efficient. The grounds were doubled, the glasshouse area expanded to 1 ha, a phytotron built, and equipment modernized.

Studies cover the whole range of horticulture, with only limited specialization in, for instance, fruit growing or floriculture. The research must therefore cover a range of plants representing the various branches of horticulture. It is mainly concerned with factors in growth, development and regeneration.

The papers in this volume deal with many aspects of this programme. They present results of current research but do not represent a balanced review of work in progress. The editors were happy to include two papers by Dr S. J. Wellensiek, now professor emeritus. The other nine papers have been written by the scientific staff, assisted variously by a member of another department, by technical staff and by specializing students. Their collaboration emphasizes the close ties between research and instruction.

J. Doorenbos 